\title{
Antimony(III)-D, L-Tartrates Exhibit Proton-Assisted Enantioselective Binding in Solution and in the Gas Phase
}

\author{
Aruna B. Wijeratne, Sandra E. Spencer, Jose Gracia,* \\ Daniel W. Armstrong, and Kevin A. Schug \\ Department of Chemistry and Biochemistry, The University of Texas at Arlington, Arlington, TX, USA
}

\begin{abstract}
The negative ion mode ESI mass spectral analysis of antimony(III)-D- and -L-tartrate ("tartar emetic"), in association with leucine enantiomeric isotopomers, revealed remarkable protonassisted enantioselective molecular recognition phenomena. The current study infers that recognition of amino acids by antimony(III)- $D, L$-tartrate complexes requires that the chiral selector associate a proton to become enantioselective. The dianionic selector itself failed to show enantiomeric discrimination capacity. This observation was shown to be consistent both in solution-phase targeting full scan and gas-phase targeting collision threshold dissociation (CTD) experiments. Importantly, this disparity in enantioselective binding capacity between the dianionic and the protonated monoanionic representatives of antimony(III)- $D$ - and -L-tartrates could only be clearly revealed by ESI-MS and tandem mass spectrometry experiments as described herein. This finding urges a more in-depth study of mechanisms associated with exhibited enantiomeric resolving capacity of antimony tartrates in HPLC and CE applications, as well as in former ESI-MS association studies. (J Am Soc Mass Spectrom 2009, 20, 2100-2105) (C) 2009 American Society for Mass Spectrometry
\end{abstract}

$\mathrm{I}$ nextricably tied to the notion of chirality through their incorporation of tartaric acid [1], metaltartrates have been the subject of research in asymmetric catalysis [2], chiral separations [3-6], and medicinal chemistry $[7,8]$. Antimony(III)-L-tartrate, known as "tartar emetic" when administered as a dipotassium salt [9], is believed to exist primarily as a doubly-charged binuclear tartrato(4-)-metal-bridged complex as shown in Figure 1. Antimony(III)- $L$-tartrate has enjoyed an especially turbulent history as a therapeutic indication, but it has shown significant utility as an analytical separations reagent, as an antifilarial drug for treatment of schistosomal blood flukes (schistosomiasis), and as an antibiotic $[9,10]$. Despite these uses, the mechanistic basis for understanding the modes of enantioselective molecular recognition by antimony tartrates has remained somewhat a mystery. Electrospray ionizationmass spectrometry (ESI-MS), in particular, is attractive for investigating molecular recognition phenomena [11-13]. Focusing on a relevant model for biomolecular recognition, specifically amino acids, it was hypothesized that ESI-MS-based binding experiments would be able to provide further insight into the enantioselective recognition capacity of antimony(III)- $D$ - and $-L$-tartrates

Address reprint requests to Dr. K. A. Schug, Department of Chemistry and Biochemistry, The University of Texas at Arlington, 700 Planetarium Pl., Campus Box 19065, Arlington, TX, USA. E-mail: kschug@uta.edu

* Current address: Schuit Institute of Catalysis, Eindhoven University of Technology, P.O. Box 513, 5600 MB Eindhoven, The Netherlands.

and, potentially, guide further research on elucidating the reported biological activity of these compounds.

Arakawa et al. were the first to investigate the enantioselective binding by potassium antimony(III)- $D$ - and $-L$-tartrate to Co(III) complex and 2-thiazolidinecarboxylic acid enantiomers using ESI-MS [14-16]. Importantly, the results of these MS-based experiments were shown to be consistent with those from independent solution phase measurements. For instance, enantioselective association of antimony(III)- $D$ - and - $L$-tartrate with $C$ (III) complexes observed in ion-exchange chromatographic experiments correlated well with data from ESI-MS based solution-phase targeting experiments [14]. Also, the time-dependent racemization of 2-thiazolidinecarboxylic acid (2-THC) enantiomers in solution was effectively tracked in single-stage mass spectra when antimony(III)- $D$ - and - $L$-tartrate selectors were utilized [15]. These correlations between solution-phase phenomena and ESI mass spectra may be due in part to the use of acetonitrile/water (ACN/ $\mathrm{H}_{2} \mathrm{O}$ ) solvent systems. Recent reports by Kass et al. show solution phase species are produced and recorded in respective mass spectra when $\mathrm{ACN} / \mathrm{H}_{2} \mathrm{O}$ (compared with $\mathrm{MeOH} / \mathrm{H}_{2} \mathrm{O}$ ) mixtures are employed as the electrospray solvent [17-19]. Nevertheless, while metaltartrates have been demonstrated to be useful for enantioselective resolution of a variety of compound classes in the solution phase [16], a general model for describing their relevant binding chemistry is still missing.

Competitive binding (solution phase-targeting) and collision threshold dissociation (gas-phase targeting) ex- 


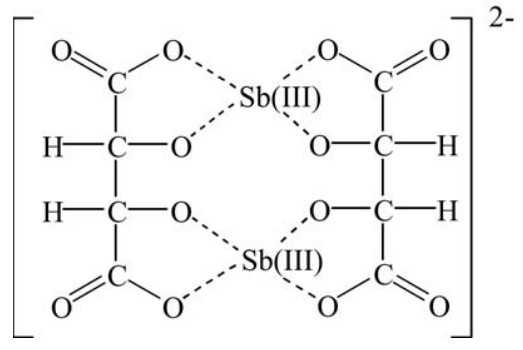

Figure 1. Doubly charged binuclear tartrato(4-)-antimony(III) bridged complex.

periments between isotopomeric enantiomers of the amino acid leucine (Leu) and disodium antimony- $D$ and - $L$-tartrates were performed to study enantioselective association and dissociation in this system. Interestingly, a remarkable charge-state-dependent (proton-assisted) enantioselectivity was observed in both solution-phase and gas-phase measurements; the protonated monoanion of antimony(III)-D- and - $L$-tartrate exhibited significant enantioselective association/dissociation with leucine enantiomers in a cross-chiral (reciprocal) fashion. Conversely, the dianionic form failed to show enantioselective recognition. Overall, the results for both ion forms were observed to be consistent in solution-phase targeting and in gas-phase experiments.

Disodium antimony(III)- $L$-tartrate $\left(\left[\mathrm{Na}_{2}\left[\mathrm{Sb}_{2}-L\right.\right.\right.$-tar $\left.\left.{ }_{2}\right]\right)$ was first analyzed in the negative-ionization mode (100 $\mu \mathrm{M}$ solution in 75:25 acetonitrile $(\mathrm{ACN}) / \mathrm{H}_{2} \mathrm{O}(\mathrm{vol} / \mathrm{vol})$ with $100 \mathrm{mM}$ formaldehyde). All measurements were performed using a Thermo LCQ Deca XP ion trap instrument (Thermo-Fisher Scientific, Inc., San Jose, CA, USA) equipped with a conventional electrospray ion source. The solvent system (75:25 ACN/ $\mathrm{H}_{2} \mathrm{O}$ $\{\mathrm{vol} / \mathrm{vol}\})$ was chosen to be consistent with prior antimony(III)-D, L-tartrate ESI-MS association studies [14-16] and to enhance the probability of observing ions characteristic of solution phase equilibria in singlestage mass spectra [17-19]. Formaldehyde was incorporated in the solution to reduce noise and enhance signal quality of negative-ion spectra according to prior reports in the literature [20]. The disodium salt of antimony tartrate was used instead of the potassium salt (tartar emetic) due to the reported reduced toxicity of the former [21]. In the spectra, a doubly-charged $\left[\mathrm{Sb}_{2}-\right.$ $\left.L-\operatorname{tar}_{2}\right]^{2-}$ (268.1 Th) ion was observed, accompanied also by protonated $\left.\left\{\left[\mathrm{Sb}_{2}-L-\operatorname{tart}\right)_{2}\right][\mathrm{H}]\right\}^{-}(536.8 \mathrm{Th})$ and sodiated $\left\{\left[\mathrm{Sb}_{2}-L-\operatorname{tar}_{2}\right][\mathrm{Na}]\right\}^{-}(558.9 \mathrm{Th})$ singly-charged anion forms (Supplementary Figure 1, which can be found in the electronic version of this article).

Competitive binding experiments were then performed to measure the differential association exhibited by both antimony(III)- $D$ - and - $L$-tartrate (in separate experiments) with enantiomeric isotopomers of leucine (D-Leu versus L-d10-Leu). Leucine was chosen as a representative biologically-relevant amino acid and the d10-deuteration of L-Leu allowed observation of wellseparated diastereomeric complex ion signals in representative mass spectra, as shown in Figure 2. Diastereomeric ionic complexes were observed only at 333.3 and

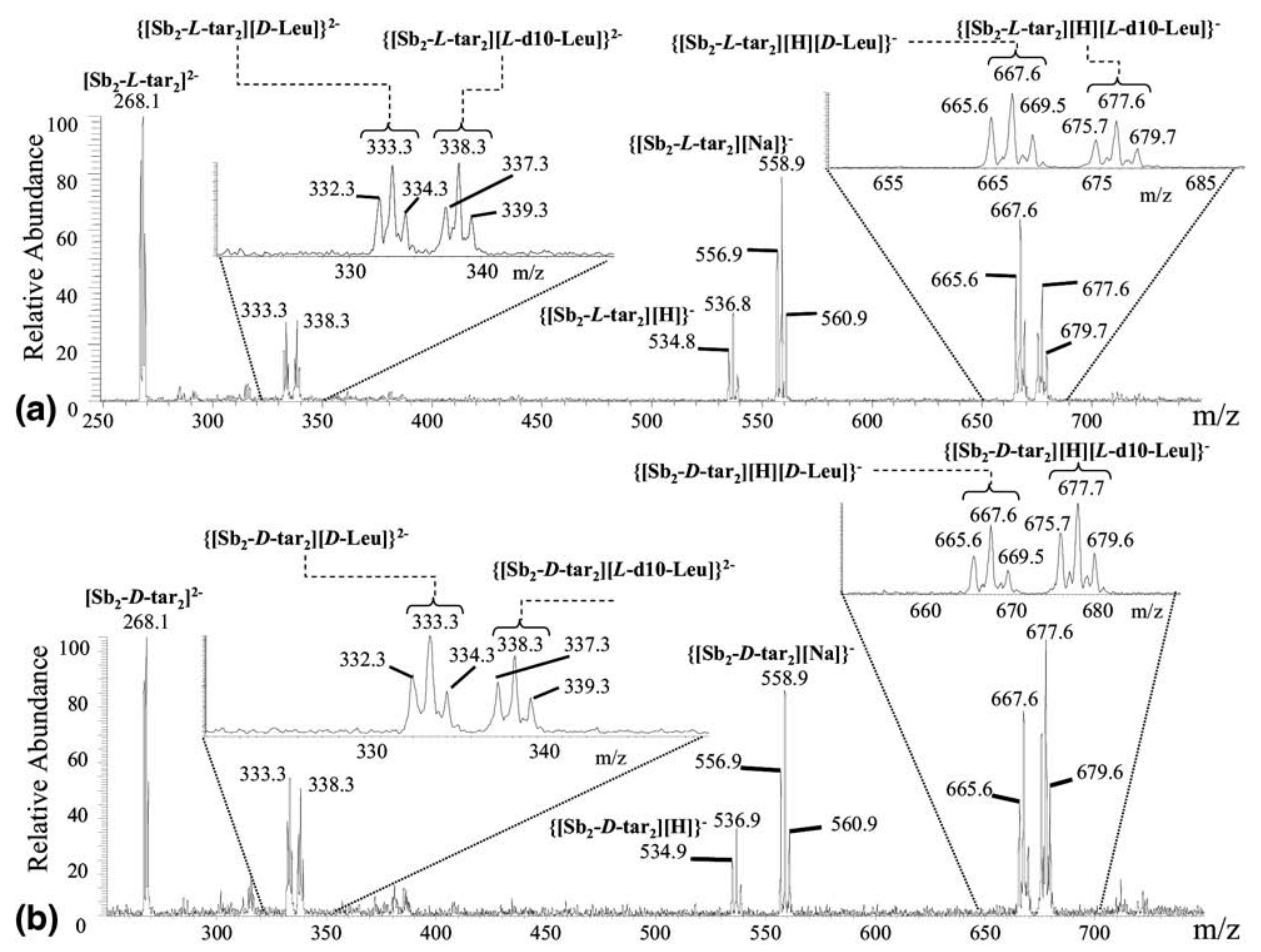

Figure 2. Competitive binding ESI mass spectra obtained by direct infusion of a solution containing equimolar $(100 \mu \mathrm{M})$ (a) $D$-Leu, $L$-d10-Leu and $\mathrm{Na}_{2}\left[\mathrm{Sb}_{2}-L\right.$-tar 2$]$ and (b) $D$-Leu, L-d10- Leu and $\mathrm{Na}_{2}\left[\mathrm{Sb}_{2}-D-\operatorname{tar}_{2}\right]$ in $\mathrm{CH}_{3} \mathrm{CN} / \mathrm{H}_{2} \mathrm{O}(75 / 25 \mathrm{vol} / \mathrm{vol})$ with $100 \mathrm{mM} \mathrm{HCHO}$. 
667.5 Th values (Figure 2a, b, insets), despite the use of the disodium salt for preparation of solutions. The composition of each diastereomeric complex was confirmed by collision induced dissociation (Supplementary Figure 2) and $\beta$-deuterium isotope binding effects were also evaluated (e.g., $\left[\mathrm{Na}_{2}\left[\mathrm{Sb}_{2}-L\right.\right.$-tar $\left.{ }_{2}\right]+L$-Leu + L-d10-Leu) (Supplementary Figure 3).

The ionizable nature of both the selector and the amino acid selectand further warranted an evaluation of their individual charge states in the observed complexes. More specifically, observed diastereomeric complexes can be assumed to form between the selector (2-, $1-$, and neutral) and (1) neutral or zwitterionic Leu (667.5 Th corresponding to $\left\{\left[\mathrm{Sb}_{2}-\mathrm{L}-\mathrm{tar}_{2}\right][\mathrm{H}][\mathrm{Leu}]\right\}^{-}$and 333.3 Th corresponding to $\left\{\left[\mathrm{Sb}_{2}-L-\operatorname{tar}_{2}\right][\mathrm{Leu}]\right\}^{2-}$ ) or (2) anionic Leu (667.5 Th corresponding to $\left\{\left[\mathrm{Sb}_{2}-\mathrm{L}-\right.\right.$ $\left.\left.\operatorname{tar}_{2}\right][\mathrm{H}]_{2}[\mathrm{Leu}-\mathrm{H}]\right\}^{-}$and 333.3 Th corresponding to $\left\{\left[\mathrm{Sb}_{2^{-}}\right.\right.$ $\left.\left.L-\operatorname{tar}_{2}\right][\mathrm{H}][\mathrm{Leu}-\mathrm{H}]\right\}^{2-}$ ). The involvement of cationic Leu, however, can be ruled out because 333.3 Th is observed in our mass spectra and 333.3 Th (a 2- complex) cannot be assigned using [Leu $+\mathrm{H}$ ].

To identify which form of Leu exists in these observed mass spectra, similar competitive binding experiments (against $L$-d10-Leu) were performed using $\mathrm{N}$ acetylated Leu (Ac-Leu). N-acetylation ensures the formation of the anionic form of the amino acid under the solution conditions employed. Supplementary Figure 4 clearly illustrates that a very different profile of sodiated diastereomeric complexes, relative to unblocked Leu, was observed when Ac-L-Leu binding was evaluated. MS/MS experiments (Supplementary Figure $5)$ verify that the observed diastereomeric complexes formed between the selector and Ac- $L$-Leu were $\left\{\left[\mathrm{Sb}_{2}{ }^{-}\right.\right.$ $\left.\left.L-\operatorname{tar}_{2}\right][\mathrm{Na}]_{2}[\mathrm{Ac}-L-L e u-\mathrm{H}]\right\}^{-}(753.7 \mathrm{Th})$ and $\left\{\left[\mathrm{Sb}_{2}-\mathrm{L}-\right.\right.$ $\left.\left.\operatorname{tar}_{2}\right][\mathrm{Na}]_{3}[\mathrm{~N}-\mathrm{Ac}-\mathrm{L}-\mathrm{Leu}-\mathrm{H}]_{2}\right\}^{-}$(948.7 Th).

The experiments with the N-acetylated amino acid reveal important information about the ionic-states of the amino acid and the chiral selector. The lack of formation of similar diastereomeric complexes with Ac-Leu, to those formed with Leu, suggests that a charged amino (ammonium) group on the amino acid is necessary for the formation of diastereomeric complexes with $\left\{\left[\mathrm{Sb}_{2}-D, L-\operatorname{tar}_{2}\right]\right\}^{2-}$ and $\left\{\left[\mathrm{Sb}_{2}-D, L-\operatorname{tar}_{2}\right][\mathrm{H}]\right\}^{1-}$ ions. It further implicates that unblocked Leu exists in a zwitterionic form when complexed to antimony tartrate. Since Leu is a zwitterion in neutral aqueous media, this not only clarifies the ionic states of the diastereomeric complexes, it also supports the notion that solution-phase data are recorded in the single-stage mass spectral analysis.

The CAD experiments more fully clarify the predominant location of the proton in the monoanionic diastereomeric complexes. Specifically, does the proton associate to higher degree with the dianionic $\left[\mathrm{Sb}_{2}-\mathrm{D}, \mathrm{L}-\right.$ $\left.\operatorname{tar}_{2}\right]^{2-}$ host core or to the zwitterionic Leu guest ion? Collisional dissociation of the monoanionic diastereomeric complexes $\left\{\left[\mathrm{Sb}_{2}-D, L-\mathrm{tar}_{2}\right][\mathrm{H}][\mathrm{Leu}]\right\}^{1-}$ return fragment ions of $\left\{\left[\mathrm{Sb}_{2}-D, L-\operatorname{tar}_{2}\right][\mathrm{H}]\right\}^{1-}$ at 536.7 Th. This observation means that the proton affinity of dianionic
$\left[\mathrm{Sb}_{2}-D, L-\operatorname{tar}_{2}\right]^{2-}$ core is greater than that of zwitterionic Leu. If the zwitterionic amino acid had possessed a greater proton affinity than the dianionic $\left[\mathrm{Sb}_{2}-D, L-\right.$ $\left.\operatorname{tar}_{2}\right]^{2-}$, then the CAD mass spectra would have produced $\left\{\left[\mathrm{Sb}_{2}-D, L-\operatorname{tar}_{2}\right]\right\}^{2-}(268.1 \mathrm{Th})$ ions. These rationale and experiments favor the assignment of zwitterionic Leu in the complex with antimony(III)-tartrate. They also support the notion that the ionization state of antimony(III)-tartrate in the complex varies from doubly deprotonated (dianionic) to singly deprotonated (monoanionic).

Interestingly, the $\left[\mathrm{Sb}_{2}-L, D-\operatorname{tar}_{2}\right]^{2-}$ dianion and the $\left\{\left[\mathrm{Sb}_{2}-L, D-\operatorname{tar}_{2}\right][\mathrm{H}]\right\}^{-}$monoanion showed significantly different enantioselectivities. Figure 3 shows the selectivity $(\alpha)$ values, calculated as a ratio of ion abundances for each of the isotopomeric diastereomeric ion complex pairs of a given charge state. Also shown are values for competitive binding control experiments to discern any contributions from the deuterium labeling [22]. For the dianionic form, no discernable enantioselectivity was observed (Cases I and V). For the monoanionic form, a significant preference for binding $D$-Leu by $\left\{\left[\mathrm{Sb}_{2}-L-\right.\right.$ $\left.\left.\operatorname{tar}_{2}\right][\mathrm{H}]\right\}^{-}$(Case III), and a cross-chiral preference of similar magnitude for binding $L$-Leu by $\left\{\left[\mathrm{Sb}_{2}-D\right.\right.$ $\left.\left.\operatorname{tar}_{2}\right][\mathrm{H}]\right\}^{-}$(Case VII), was recorded. While deuterium isotope effects were observed, the magnitudes of these effects were less pronounced than that for the measured enantioselectivities.

To further elucidate the proton-assisted enantioselectivity observed in competitive-binding experiments, the diastereomeric ionic complexes were isolated in the quadrupole ion trap and subjected to collision threshold dissociation (CTD). In these gas-phase experiments, the stabilities of isolated ionic complexes were monitored as a function of activation voltage $[23,24](\mathrm{q}=0.250 ; 30$ ms activation time). In Figure 4, it can be seen that the

$$
\text { Selectivity }(\boldsymbol{\alpha})=\frac{\text { int }\left\{\left[\mathrm{Sb}_{2}-X-\operatorname{tar}_{2}\right][\mathrm{H}]_{\mathrm{a}}[Y-\mathrm{Leu}]\right\}^{\mathrm{p}-}}{\text { int }\left\{\left[\mathrm{Sb}_{2}-X-\operatorname{tar}_{2}\right][\mathrm{H}]_{\mathrm{a}}[Z \text {-Leu }]\right\}^{\mathrm{p}-}}
$$

\begin{tabular}{ccccccc}
\hline Case & $\boldsymbol{X}$ & $\boldsymbol{Y}$ & $\boldsymbol{Z}$ & $\mathbf{a}$ & $\mathrm{p}-$ & $\boldsymbol{\alpha}$ \\
\hline I & $L$ & $D$ & $L-\mathrm{d}_{10}$ & 0 & $2-$ & $1.09 \pm 0.15$ \\
II & $L$ & $L$ & $L-\mathrm{d}_{10}$ & 0 & $2-$ & $0.96 \pm 0.14$ \\
III & $L$ & $D$ & $L-\mathrm{d}_{10}$ & 1 & $1-$ & $1.62 \pm 0.20$ \\
IV & $L$ & $L$ & $L-\mathrm{d}_{10}$ & 1 & $1-$ & $1.13 \pm 0.07$ \\
V & $D$ & $L-\mathrm{d}_{10}$ & $D$ & 0 & $2-$ & $0.82 \pm 0.15$ \\
VI & $D$ & $L-\mathrm{d}_{10}$ & $L$ & 0 & $2-$ & $0.77 \pm 0.07$ \\
VII & $D$ & $L-\mathrm{d}_{10}$ & $D$ & 1 & $1-$ & $1.65 \pm 0.42$ \\
VIII & $D$ & $L-\mathrm{d}_{10}$ & $L$ & 1 & $1-$ & $0.81 \pm 0.03$ \\
\hline
\end{tabular}

Figure 3. Calculated average selectivity values $(n=5)$ and standard deviations from competitive binding experiments according to the given standard equation. $X$ denotes the stereochemistry of the tartrates, $Y$ and $Z$, respectively, denote the configuration of Leu in the numerator and denominator, a denotes the number of protons associated with the complex, and p- denotes the charge state of the complex. Cases for evaluation of enantioselectivity (I, III, V, VII) are shaded in grey. Control experiments for determination of deuterium isotope effect contributions are shown in cases II, IV, VI, and VIII. 
$\left\{\left[\mathrm{Sb}_{2}-L-\operatorname{tar}_{2}\right][\mathrm{H}][D, L-\mathrm{Leu}]\right\} \bullet\left\{\left[\mathrm{Sb}_{2}-L-\operatorname{tar}_{2}\right][\mathrm{H}]\right\} \cdot+D, L-\mathrm{Leu}$

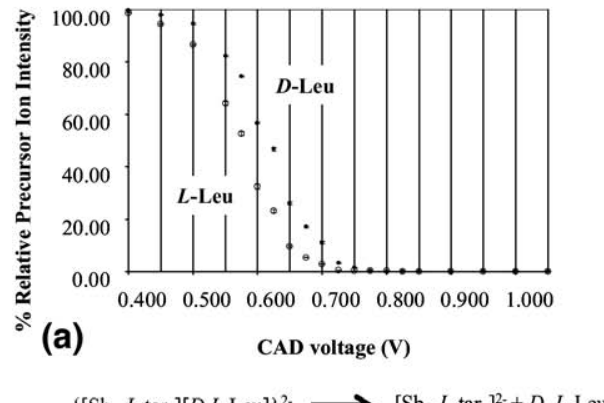

$\left\{\left[\mathrm{Sb}_{2}-L-\operatorname{tar}_{2}\right][D, L \text {-Leu }]\right\}^{2-} \longrightarrow\left[\mathrm{Sb}_{2}-L-\operatorname{tar}_{2}\right]^{2-}+D, L-$ Leu

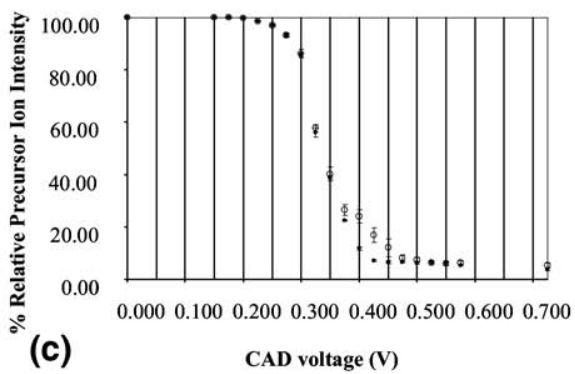

$\left\{\left[\mathrm{Sb}_{2}-D-\operatorname{tar}_{2}\right][\mathrm{H}][D, L\right.$-Leu $\left.]\right\} \cdot\left\{\left[\mathrm{Sb}_{2}-D-\operatorname{tar}_{2}\right][\mathrm{H}]\right\} \cdot D, L$-Leu

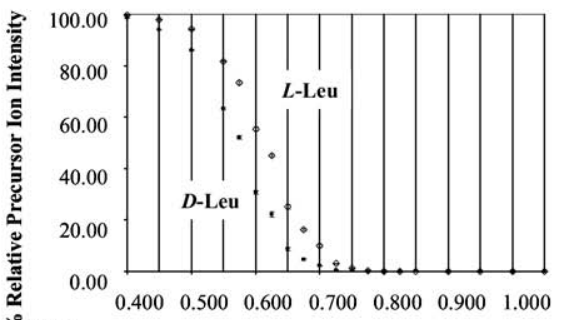

(b)

CAD voltage (V)
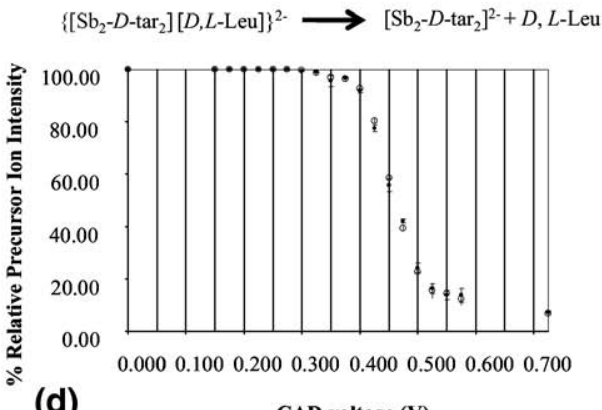

CAD voltage (V)

Figure 4. Collision threshold dissociation of diastereomeric ion complexes: (a) $\left\{\left[\mathrm{Sb}_{2}-L-\operatorname{tar}_{2}\right][\mathrm{H}][D-\right.$ Leu $]\}^{-}$(filled circle) and $\left\{\left[\mathrm{Sb}_{2}-\mathrm{L}-\mathrm{tar}_{2}\right][\mathrm{H}][\mathrm{L} \text {-Leu }]\right\}^{-}$(open circle); (b) $\left\{\left[\mathrm{Sb}_{2}-D \text { - } \operatorname{tar}_{2}\right][\mathrm{H}][D-\mathrm{Leu}]\right\}^{-}$(filled circle) and $\left\{\left[\mathrm{Sb}_{2}-D-\operatorname{tar}_{2}\right][\mathrm{H}][\mathrm{L} \text {-Leu }]\right\}^{-}$(open circle); (c) $\left\{\left[\mathrm{Sb}_{2}-L-\operatorname{tar}_{2}\right][D-\mathrm{Leu}]\right\}^{2-}$ (filled circle) and $\left\{\left[\mathrm{Sb}_{2}-L-\operatorname{tar}_{2}\right][L-\mathrm{Leu}]\right\}^{2-}$ (open circle); (d) $\left\{\left[\mathrm{Sb}_{2}-D-\operatorname{tar}_{2}\right][D-\mathrm{Leu}]\right\}^{2-}$ (filled circle) and $\left\{\left[\mathrm{Sb}_{2}-D-\operatorname{tar}_{2}\right]\right.$ $[L$-Leu $]\}^{2-}$ (open circle) in a quadrupole ion trap. Data points are reported as average values $(n=3)$ with error bars representing one standard deviation from the mean.

overall trend for selective dissociation in the gas phase is consistent with that observed in the solution phase. For the monoanionic diastereomeric complexes, a distinct enantioselective binding preference was observed, where a higher activation voltage was required to dissociate $D$-Leu from $\left\{\left[\mathrm{Sb}_{2}-L \text {-tar } 2\right][\mathrm{H}][D \text {-Leu }]\right\}^{-}$(Figure 4a). Similarly, the complex between $\left\{\left[\mathrm{Sb}_{2}-D-\operatorname{tar}_{2}\right][\mathrm{H}]\right\}^{-}$ and $L$-Leu was more stable than that for $D$-Leu (Figure $4 b)$. Although absolute binding energies are difficult, if not impossible, to determine due to the multi-collision environment in the ion trap, the differences between voltages required to dissociate $50 \%$ of the precursor ion complexes $\left(\mathrm{V}_{50}\right)$ can be used as a measure of relative stability.

The average $\mathrm{V}_{50}$ values $(n=3)$ for dissociation of $\left\{\left[\mathrm{Sb}_{2}-L-\operatorname{tar}_{2}\right][\mathrm{H}][D-\mathrm{Leu}]\right\}^{-},\left\{\left[\mathrm{Sb}_{2}-L-\operatorname{tar}_{2}\right][\mathrm{H}][L-L e u]\right\}^{-},\left\{\left[\mathrm{Sb}_{2^{-}}\right.\right.$ $\left.\left.D-\operatorname{tar}_{2}\right][\mathrm{H}][\mathrm{L}-\mathrm{Leu}]\right\}-$, and $\left\{\left[\mathrm{Sb}_{2}-D-\operatorname{tar}_{2}\right][\mathrm{H}][D-\mathrm{Leu}]\right\}^{-}$diastereomeric ions obtained from the threshold dissociation plots were $0.615 \pm 0.005 \mathrm{~V}, 0.575 \pm 0.005 \mathrm{~V}, 0.610 \pm$ $0.005 \mathrm{~V}$, and $0.570 \pm 0.005 \mathrm{~V}$, respectively. The differences in $\mathrm{V}_{50}$ values (with error propagation) which are indicative of $\Delta(\Delta \mathrm{G})$ for the dissociation of the diastereomeric complexes were $0.040 \pm 0.007 \mathrm{~V}(D$-Leu $>$ L-Leu with $\left.\left\{\left[\mathrm{Sb}_{2}-L-\operatorname{tar}_{2}\right][\mathrm{H}]\right\}^{-}\right)$and $0.040 \pm 0.007 \mathrm{~V}(\mathrm{~L}$-Leu $>$ $D$-Leu with $\left.\left\{\left[\mathrm{Sb}_{2}-D-\operatorname{tar}_{2}\right][\mathrm{H}]\right\}^{-}\right)$, demonstrating enantioselective binding in the gas phase with a perfect quantitative cross-chiral relationship (assuming the constant of proportionality between $V_{50}$ and $\Delta G$ values are constant during all CAD experiments). A similar analysis was carried out for evaluating the results from dissociation of the dianionic diastereomeric complexes (Figure 4c, d). The experiments indicated no enantioselective dissociation in the gas phase for the dianionic forms, which is consistent with solution-phase based competitive binding results.

While noncorrelation between solution-phase and gas-phase binding preference is common, this marked correlation of proton-assisted enantioselective discrimination capacity of antimony(III)- $D$ - and - $L$-tartrate between solution-phase and gas-phase association and dissociation phenomena can provide some insight into the binding chemistry between antimony(III)- $D, L$ tartrates and leucine enantiomers. Specifically, for the protonated monoanionic system, the solvent can be assumed to play a minor role relative to the stereochemical orientation of the associates in providing enantioselective binding. In other words, solvation is not necessarily needed to maintain a delicate balance of noncovalent forces, contrary to that shown for other enantioselective systems [25]. Further studies incorporating different solution conditions (\% organic, $\mathrm{pH}$, and ionic strength) are needed to confirm this assertion.

Of greater interest is the nature of proton-assistance, which gives rise to enantioselective binding. This finding suggests that the display of functional motifs responsible for enantioselective binding to leucine is significantly different between the dianionic and the protonated monoanionic forms. Assuming that complex formation is driven primarily by the attraction between the ammonium group on the guest ion and 
the negatively-charged $\left\{\left[\mathrm{Sb}_{2}-D, L-\operatorname{tar}_{2}\right]\right\}^{2-}$ and $\left\{\left[\mathrm{Sb}_{2}-D, L-\right.\right.$ $\left.\left.\operatorname{tar}_{2}\right][\mathrm{H}]\right\}^{-}$ions, further speculation can be made about the nature of the enantioselective recognition process. For a zwitterionic amino acid, the dianionic $\left\{\left[\mathrm{Sb}_{2}-\mathrm{D}, \mathrm{L}-\right.\right.$ $\left.\left.\operatorname{tar}_{2}\right]\right\}^{2-}$ host ion would complex with the ammonium portion; however, the free carboxylate group could potentially be repelled by the dianion. This arrangement might lead to a poor orientation for enantioselective recognition. For complex formation with the monoanion, although the amino acid is zwitterionic, the free carboxylate might be able to hydrogen bond through the extra proton present on the $\left\{\left[\mathrm{Sb}_{2}-D, L-\operatorname{tar}_{2}\right][\mathrm{H}]\right\}^{1-}$ selector ion. Thus, an additional noncovalent contact might result, and ultimately give rise to the observed discrimination of the amino acid enantiomers by the monoanion, whereas the dianion lacks this capability.

To investigate these phenomena more fully, both theoretical computational and solution phase NMR experiments have been initiated [26]. Preliminary computational results indicate that the lack of enantioselectivity observed for the dianionic form is due to the presence of an additional low-energy conformation in equilibrium with the $\mathrm{X}$-ray-predicted crystallographic form. These forms appear to exhibit opposing enantioselectivities, manifesting experimentally in an overall lack of enantioselectivity observed for the dianion form during ESI-MS measurements. For the protonated case, which has never been previously investigated in this manner, a single dominant conformation has been preliminarily isolated, explaining the observation of its enantioselective binding capacity in the mass spectra. The detailed computations necessary to fully explain this behavior require significant time to complete. These results, along with data from NMR experiments and ESI-MS data for additional analyte enantiomers, are needed to fully elaborate the mechanistic basis for the observations reported here, and will be reported in due course.

In conclusion, fundamental mass spectrometric investigations have provided key pieces of evidence towards rationalizing the enantioselective binding capacity of antimony(III)- $D$ and $L$-tartarate. It is reasonable to assume that the dianion $\left[\mathrm{Sb}_{2}-D, L-\operatorname{tar}_{2}\right]^{2-}$ is in equilibrium with the protonated monoanion $\left\{\left[\mathrm{Sb}_{2}-D, L-\right.\right.$ $\left.\left.\operatorname{tar}_{2}\right][\mathrm{H}]\right\}^{-}$in aqueous solutions. The fact that these different ion forms yield different enantioselective discrimination capacity holds promise for reconciling the use of antimony(III)- $D$ - and - $L$-tartrates as analytical separations reagents. In the work by Martin et al. [6], resolution of $\mathrm{Ru}(\mathrm{II})$ tris-diimine complexes by capillary electrophoresis was achieved at $\mathrm{pH} 2.5$, a condition where the protonated monoionic complex would be highly favored. At higher $\mathrm{pH}$ values, enantioselectivity would be expected to diminish as the dianionic form is populated. Other reports in the literature also assert the importance of $\mathrm{pH}$ on enantioselective solution phase separations [27-29]. With regard to mass spectrometry, these findings may prompt further evaluation of previous work using antimony(III)-tartrates in ESI-based enantioselective association experiments $[14,15]$ to discern if similar behavior, especially for the protonated monoanion $\left\{\left[\mathrm{Sb}_{2}-L-\operatorname{tar}_{2}\right][\mathrm{H}]\right\}^{-}$, may have been overlooked. Overall, the notion of charge-state-dependent enantioselective reactions has been previously reported in protein-ligand systems [30], but to our knowledge, this is the first report of such behavior for small molecule enantioselective binding systems, recorded in both solution-phase targeting ESI-MS and gas-phase MS/MS dissociation experiments. This study sheds new light on the dynamic nature of antimony(III)tartrate chiral selectors and prompts further investigation into a system that could indeed still be found quite useful for analytical separations (and therapeutic indications) if it can be controlled to a greater extent.

\section{Acknowledgments}

The authors acknowledge support from the University of Texas at Arlington, the Robert A. Welch Foundation (Y-0026), and the National Science Foundation (CHE-0846310). The authors also thank Professors Jennifer Brodbelt, Richard Cole, Peter Kroll, and the anonymous reviewers for helpful discussions regarding the interpretation of these results.

\section{Appendix A Supplementary Material}

Supplementary material associated with this article may be found in the online version at doi:10.1016/ j.jasms.2009.07.011.

\section{References}

1. Pasteur, L. Compt. Rend. Paris 1848, 26, 535-538.

2. Williams, I. D.; Pedersen, S. F.; Sharpless, K. B.; Lippard, S. J. Crystal Structures of Two Titanium Tartrate Asymmetric Epoxidation Catalysts. J. Am. Chem. Soc. 1984, 106, 6340-6341.

3. Tapscott, E. R.; Belford, R. L.; Paul, I. C. Stereochemistry of Tartrato (4-)-Bridged Binuclear Complexes. Coord. Chem. Rev. 1969, 4, 323-359.

4. Sun, P.; Krishnan, A.; Yadav, A.; Singh, S.; MacDonnell, F. M.; Armstrong, D. W. Enantiomeric Separations of Ruthenium(II) Polypyridyl Complexes Using High-Performance Liquid Chromatography (HPLC) with Cyclodextrin Chiral Stationary Phases (CSPs). Inorg. Chem. 2007, 46, 10312-10320.

5. Nakazawa, H.; Yoneda, H. Chromatographic Study of Optical Resolution. II. Separation of Optically Active Cobalt(III) Complexes Using Potassium Antimony d-Tartrate as Eluent. J. Chromatogr. 1978, 160, 89-99.

6. Martin, S. E.; Connatser, R. M.; Kane-Maguire, N. A. P.; Wheeler, J. F. Capillary Electrophoresis with Laser-Induced Fluorescence Detection for Chiral Analysis and DNA Binding Studies of Ruthenium(II) TrisDiimine Complexes. Anal. Chim. Acta 2001, 445, 21-27.

7. Plimmer, H. G.; Bateman, H. R. Further Results of the Experimental Treatment of Trypanosomiasis; Being a Progress Report of a Committee of the Royal Society. Proc. Royal Soc. London B 1908, 80, 477-487.

8. Tracy, J. W.; Webster, L. T. Chemotherapy of Parasitic Infections. In Goodman and Gilman's the Pharmacological Basis of Therapeutics, Hardman, J. G., Limbird, L. E., Molinoff, P. B., Ruddon, R.W., Gilman, A. G., Eds.; Section IV, 9th ed.; McGraw-Hill Book Co.: New York, 1996; pp. 987-1008.

9. Duffin, J.; René, P. "Anti-moine; anti-biotique": The Public Fortunes of the Secret Properties of Antimony Potassium Tartrate (Tartar Emetic). J. Hist. Med. Allied Sci. 1991, 46, 440-456.

10. Mansour, T. E. Chemotherapy of Parasitic Worms: New Biochemical Strategies. Science 1979, 205, 462-469.

11. Brodbelt, J. S. Probing Molecular Recognition by Mass Spectrometry. Int. J. Mass Spectrom. 2000, 200, 57-69.

12. Gingras, A.-C.; Gstaiger, M.; Raught, B.; Aebersold, R. Analysis of Protein Complexes Using Mass Spectrometry. Nature Rev. 2007, 8, 645-654.

13. Schug, K. A. Solution Phase Enantioselective Recognition and Discrimination by Electrospray Ionization-Mass Spectrometry: State-of-the-Art 
Methods, and an Eye Towards Increased Throughput Measurements. Combinat. Chem. High Throughput Screen. 2007, 10, 301-316.

14. Arakawa, R.; Kobayashi, M.; Ama, T. Chiral Recognition in Association Between Antimony Potassium Tartrate and bis(L-Alaninate)Ethylenediamine Cobalt(III) Complexes Using Electrospray Ionization Mass Spectrometry. J. Am. Soc. Mass Spectrom. 2000, 11, 804-808.

15. Arakawa, R: Kobayashi, M. Fukuo, T. Shiraiwa T Studies on the Association of 2-Thiazolidinecarboxylic Acid and Antimony Potassium Tartrate: Chiral Recognition and Prediction of Absolute Configuration by Electrospray Ionization Mass Spectrometry. Rapid Commun. Mass Spectrom. 2001, 15, 685-689.

16. Wijeratne, A. B.; Schug, K. A. Molecular Recognition Properties of Tartrates and Metal-Tartrates in Solution and Gas Phase. J. Sep. Sci. 2009, 32, 1537-1547.

17. Tian, Z.; Kass, S. R. Does Electrospray Ionization Produce Gas-Phase or Liquid-Phase Structures? J. Am. Chem. Soc. 2008, 130, 10842-10843.

18. Tian, Z.; Wang, X.; Wang, L.; Kass, S. R. Are Carboxyl Groups the Most Acidic Sites in Amino Acids? Gas-Phase Acidities, Photoelectron Spectra, and Computations on Tyrosine, p-Hydroxybenzoic Acid, and Their Conjugate Bases. J. Am. Chem. Soc. 2009, 131, 1174-1181.

19. Tian, Z.; Kass, S. R. Gas-Phase Versus Liquid-Phase Structures by Electrospray Ionization MassS. Angew. Chem. 2009, 48, 1321-1323.

20. Wu, Z.; Gao, W.; Phelps, M. A.; Wu, D.; Miller, D. D.; Dalton, J. T. Favorable Effects of Weak Acids on Negative-Ion Electrospray Ionization Mass Spectrometry. Anal. Chem. 2004, 76, 839-847.

21. Kita, K.; Shiomi, K.; Omura, S. Advances in Drug Discovery and Biochemical Studies. Trends Parasitol. 2007, 23, 223-229.

22. Schug, K. A.; Maier, N. M.; Lindner, W. Deuterium Isotope Effects Observed During Competitive Binding Chiral Recognition Electrospray Ionization-Mass Spectrometry of Cinchona Alkaloid-Based Systems. J. Mass Spectrom. 2006, 41, 157-161.
23. Wan, K. X.; Gross, M. L.; Shibue, T. Gas-Phase Stability of DoubleStranded Oligodeoxynucleotides and Their Noncovalent Vomplexes with DNA-Binding Drugs as Revealed by Collisional Activation in an Ion Trap. J. Am. Soc. Mass Spectrom. 2000, 11, 450-457.

24. Colorado, A.; Brodbelt, J. S. An Empirical Approach to Estimation of Critical Energies by Using a Quadrupole Ion Trap. J. Am. Soc. Mass Spectrom. 1996, 7, 1116-1125.

25. Schug, K. A.; Joshi, M. D.; Fryčák, P.; Maier, N. M.; Lindner, W. Investigation of Monovalent and Bivalent Enantioselective Molecular Recognition by Electrospray Ionization-Mass Spectrometry and Tandem Mass Spectrometry. J. Am. Soc. Mass Spectrom. 2008, 19, $1629-1642$.

26. Wijeratne, A. B.; Gracia, J.; Armstrong, D. W.; Schug, K. A. ChargeState-Dependent Enantioselective Discrimination of Leucine Enantiomers by Antimony(III)-D/L-Tartrate Elucidated by ESI-MS, Computational Modeling and ${ }^{1} \mathrm{H}-\mathrm{NMR}$. Proceedings of the 57th ASMS Conference on Mass Spectrometry and Allied Topics; Philadelphia, PA, May, 2009.

27. Wang, X.; Lee, J.-T.; Armstrong, D. W. Separation of Enantiomers by Capillary Electrophoresis Using Pentosan Polysulfate. Electrophoresis 1999, 20, 162-170

28. Trapp, O.; Trapp, G.; Kong, J.; Hahn, U.; Vogtle, F.; Schurig, V. Probing the Stereointegrity of Troger's Base-a Dynamic Electrokinetic Chromatographic Study. Chem. Eur. J. 2002, 8, 3629-3634.

29. Bustos, E.; Garcia, J. E.; Bandala, Y.; Godinez, L. A.; Juaristi, E. Enantioselective Recognition of Alanine in Solution with Modified Gold Electrodes Using Chiral PAMAM Dendrimers G4.0. Talanta 2009, 78, 1352-1358.

30. Camara, E.; Green, M. K.; Penn, S. G.; Lebrilla, C. B. Chiral Recognition is Observed in the Deprotonation Reaction of Cytochrome $c$ by (2R)and (2S)-2-Butylamine. J. Am. Chem. Soc. 1996, 118, 8751-8752. 